Access this article online

Website:

onbt.scholasticahq.com

DOI:

10.18639/ONBT.2016.03.1257

\title{
Phyllodes tumor of the breast: Wolf inside the sheep's skin!
}

\author{
Tabassum Wadasadawala1', Monali Swain'1, Jyoti Bajpai²
}

\begin{abstract}
:
Phyllodes tumor, previously known as cystosarcoma phyllodes, is a rare fibro-epithelial tumor of breast constituting $<1 \%$ of all the breast tumors. It is classified into benign, borderline, and malignant subtypes depending upon the histological criteria defined by the World Health Organization and also has an independent prognostic significance. Accurate pretreatment histological diagnosis is important for the optimal management of phyllodes tumor so that low recurrence rates, improved survival, and optimal long-term cosmetic result can be achieved. Despite surgery being the standard of care, the best type of surgery for each histological type is yet to be defined. The higher rate of local recurrence after surgery alone in borderline and malignant phyllodes tumor raises the question regarding the need of adjuvant treatment, especially radiotherapy, which remains underutilized. The perspective of the current review is to provide the state-of-the-art management of phyllodes tumor of the breast and highlight the risk factors associated with recurrence.
\end{abstract}

Key words:

Phyllodes tumor, adjuvant therapy, breast, malignant phyllodes

\section{Introduction}

Dhyllodes tumors (PTs) are rare, biphasic, 1 fibro-epithelial lesions constituting 0.3$0.9 \%$ of all mammary tumors and $2-3 \%$ of fibro-epithelial neoplasm of the breast. ${ }^{[1,2]}$ The tumor consists of both epithelial and stromal components, the former differentiates it from other stromal sarcomas and the latter, which forms an essential microscopic feature of this neoplasm, has the potential for metastasis. In 1838, Johannes Muller used the term "cystosarcoma phyllodes" to describe this tumor, which was originally considered to be a benign tumor. The name was a misnomer as the cystic component is rare and "sarcoma" defines the malignant potential. There have been 60 different nomenclatures that define this tumor. $^{[3]}$ In 1981, World Health Organization (WHO) appropriately termed the tumor as "phyllodes tumor." $[4]$ The term "PT" represents a broad range of fibro-epithelial diseases spanning from benign, relatively indolent tumors to malignant neoplasm capable of rapid disease progression and distant spread. Preoperative accurate pathological diagnosis guides correct surgical planning, which is the cornerstone of management and reduces the extent of repeat surgery to achieve negative margins. ${ }^{[5,6]}$ This review enables readers to get in-depth knowledge about the presentation, diagnosis, important risk factors for locoregional recurrence, and challenging management aspects based on current evidence.

\section{Clinical Presentation and Natural History}

The age incidence pattern shows that the risk of cystosarcoma phyllodes peaks in the 4th to 5 th decade although it occurs in women of all age groups from the 2 nd to 8 th decade. ${ }^{[2]}$ The age patterns vary by race and ethnicity, with Asian and Latin American patients significantly younger than non-Latin white patients. Few cases have been reported in men, and these have consistently been associated with the presence of gynecomastia. ${ }^{[7]}$ The tumor can be multifocal (2-5 lumps) in up to $12 \%$ of cases and bilateral in up to $3.5 \%$ of cases. ${ }^{[8,9]}$ The typical presentation of a PT is a painless palpable slow-growing mass followed by sudden rapid acceleration in about $20-30 \%$ of patients. The average diameter at presentation is around $4-5 \mathrm{~cm}$, though some tumors may reach a very large size (giant phyllodes $>10 \mathrm{~cm}$ ) and can completely replace the breast tissue. They are almost always freely mobile from the chest wall. Skin breakdown may occur not from infiltration but rather from pressure necrosis. Lymphatic spread is rare in PT. Though clinical axillary lymph node involvement may be seen in $10-15 \%$ of patients, pathological involvement is seen in less than $1 \%$ of cases. ${ }^{[10-13]}$ The clinical lymphadenopathy is due to reactive hyperplasia as a result of necrosis or secondary infection. ${ }^{[12]}$

PTs recur locally irrespective of histological grade with higher incidence in borderline 
and malignant subtypes. ${ }^{[14,15]}$ Moreover, malignant forms can behave more aggressively as they have a propensity for distant metastases and thereby affect survival. ${ }^{[16]}$

\section{Diagnosis}

Triple assessment (clinical, radiological, and cytological or histological) forms the fundamental evaluation for PT as with other breast lumps. There are no definite clinical criteria to differentiate between cystosarcoma and fibroadenoma. ${ }^{[17]}$ Sonographically, the presence of inhomogeneous, solidappearing mass with the presence of cleft-like cystic areas within the lobulated lesion more likely favors the diagnosis of PT. ${ }^{[18]}$ On magnetic resonance imaging (MRI), these tumors present as oval, round, or lobulated circumscribed masses with high signal intensity on T-2 weighted images. ${ }^{[19]}$ There are also no reliable radiological criteria to distinguish between benign and malignant subtypes of PT. ${ }^{[20]}$ Biopsy is essential to establish the diagnosis. Excision biopsy is preferred over core needle biopsy as the latter does not grasp the stromal element that is essential in subclassifying the lesion and guiding further surgical management.

\section{Histological Classification}

Histologically, PT consists of epithelial cells and varying morphology of connective tissue. Stromal component may be bland resembling a fibroadenoma or accompanied by cellular atypia resembling soft tissue sarcoma. Regressive changes such as necrotic or cystic degeneration and intratumoral bleeding may appear in large tumors.

The incidence of malignant PT widely varies from 10 to $54 \%$ (average estimate 25\%). ${ }^{[21]}$ One possible explanation for such a disparity may be the low incidence of PT, resulting in small patient groups observed in individual studies. Moreover, different workers have used different histological criteria for subclassifying these tumors. In the earlier times, most authors recognized PT as the benign and malignant variants only. However, in 1981, the WHO introduced the category of borderline PT to highlight a gray zone in grading PT of the breast. The primary reason for defining the borderline malignant category, then, was to prevent the overdiagnosis of malignancy. Thus, the term "PT" was adopted by the WHO and was histologically subclassified as benign, borderline, or malignant types based on a semiquantitative evaluation of various histological criteria of the stromal component [Table 1]. ${ }^{[22]}$

\section{Treatment}

Surgery

The spectrum of biologic behavior of PT varies at one end from a least aggressive form similar to fibroadenoma, wherein tumors reoccur only locally following excision, to more aggressive tumors that metastasize distantly, similar to sarcomas, at the other end. Surgery remains the mainstay of management. Recommended surgical options vary from wide local excision (WLE) to mastectomy. The aim of surgery should be complete removal of the tumor with adequate margins. Radical surgery in the form of mastectomy was the treatment option of choice until the late 1970s. Nowadays, a more conservative surgical approach is preferred based on the notion that local recurrences (LR) do not appear to be related to the systemic spread of the disease. ${ }^{[23,24]}$ However, studies have reported results contrary to this view too. ${ }^{[15,25]}$ The recent trend towards breast conservation has had a variable impact on the risk of local recurrence (reported as $20-30 \%$ for malignant tumors) without an apparent adverse effect on overall survival (OS). ${ }^{[2,7,26]}$

Due to the relative rarity of the tumor and heterogeneity of surgical procedures applied by various centers, no definite conclusion regarding the appropriate surgical procedure can be drawn from the available literature. Hence, optimal extent of surgical excision is still a matter of debate particularly for borderline and malignant subtypes. Since PTs are not commonly multifocal, a majority of physicians currently suggest WLE to be an appropriate and adequate primary surgical procedure irrespective of the histopathological subtype of PT. A lumpectomy with clear margins (more than $1 \mathrm{~cm}$ based on retrospective data) is recommended for small lesions (up to a size of $3 \mathrm{~cm}$ ). Segmental resection with clear margins is recommended for larger lesions (over $3 \mathrm{~cm}$ in size). Mastectomy seems to be reserved for cases even more extensive wherein WLE will either preclude a cosmetically acceptable outcome or result in repeated positive margins. Some authors also recommend simple mastectomy without axillary dissection for malignant or histologically aggressive lesions. ${ }^{[27]}$ Regional (axillary) lymph node (LN) dissection does not add significant benefit since PTs rarely metastasize to axillary lymph nodes. ${ }^{[28]}$ Some recent studies recommend that axillary dissection should be performed only in patients with clinically suspicious nodal involvement. ${ }^{[13,29]}$

The analysis of data from the Surveillance, Epidemiology and End Results (SEER) Program for the years 1983-2002

Table 1: WHO 2009 classification of phyllodes tumor ${ }^{[22]}$

\begin{tabular}{llll}
\hline Histologic feature & Benign & Borderline & Malignant \\
\hline Stromal hypercellularity & Minimal & Moderate & Marked \\
Cellular pleomorphism & Minimal & Moderate & Marked \\
Mitosis & Few if any & Intermediate & Numerous $>10 / 10 \mathrm{HPF}$ \\
Margin & Pushing & Pushing or infiltrating & Infiltrating \\
Stromal pattern & Uniform & Heterogeneous stromal expansion & Marked stromal overgrowth \\
Heterologous stromal elements & Rare & Rare & Not uncommon \\
\hline
\end{tabular}


demonstrated a similar efficacy of wide excision and mastectomy in 821 malignant PTs in terms of cause-specific survival. ${ }^{[30]}$ Wide excision was performed in $48 \%$ and mastectomy in $52 \%$ of the patients. Adjuvant radiotherapy (RT) was given in only 9\% of the entire cohort. Excluding $25 \%$ of patients where tumor size was not known, a majority of the tumors (44\%) were less than $5 \mathrm{~cm}$. Moreover, mastectomy patients were older (age $>60$ years $32 \%$ vs. $24 \%, p=0.004$ ) and had larger tumors (tumor size $>5 \mathrm{~cm} 56 \%$ vs. $32 \%, p=$ $0.009)$ compared with wide excision. The major limitation of the SEER data was the lack of information on important histopathological risk factors, including exact histological subtype (borderline or malignant), stromal overgrowth, tumor necrosis, and surgical margins. Eligible women were identified by the behavior code representing malignant disease. The clinical reasoning for mastectomy versus wide excision was also not available. Moreover, SEER does not contain data on local or distant failures, information that would be necessary to determine event-free survival or for conclusions regarding patterns of failure. Of the total 157 deaths, 72 deaths (46\%) were attributed to recurrent or progressive disease in the breast at a very short median follow-up of 1.8 years, which is very alarming and points toward the probable role of adjuvant therapy. Another important finding reported was improved cause-specific survival in patients younger than 60 years, which is also supported by other series. ${ }^{[27,31]}$

Predictive factors of local failure: is surgery enough? PTs recur regardless of histology, although the risk of local recurrence is lower in benign forms (5-15\%) and significantly higher in borderline (4.7-30\%) and malignant cases $(30-65 \%){ }^{[14,15]}$ Approximately about 22\% (range 10-30\%) of borderline or malignant tumors give rise to distant metastases. The most frequent site of distant metastasis is lung followed by soft tissue, bone, and pleura. ${ }^{[16]}$ The 5-year disease-free survival rates for benign, borderline, and malignant tumors are 96,74 , and $66 \%$, respectively. ${ }^{[2]}$

A number of grading criteria and surgical approaches have been employed in the treatment of PT. This is reflected in a wider range of distribution of incidence of malignant histology as well as local recurrence rates. Moreover, most of the series have reported clinical outcome according to various prognostic factors irrespective of histological subtype. Additionally, limited numbers of malignant and borderline cases in the reported studies have not enabled any consistent conclusion about the predictors of outcome or role of adjuvant therapies.

There is ample evidence to suggest that close or positive margin status is the most important predictor of local failure independent of all other risk factors [Tables $2 \mathrm{a}$ and $2 b] \cdot{ }^{[8,9,24,25,32-40]}$ The incidence of local failure is higher when margin is positive rather than close. It is important to note that the definition of negative margins (i.e., $1 \mathrm{~cm}$ ) has been arbitrarily derived from the retrospective studies. Negative margin was achieved in $29.6-100 \%$ of patients at the time of initial surgery in various studies [Table 2a]. The median margin width has not been reported in the literature. Though the incidence of positive/close margin varied from 5.9 to $66.7 \%$, revision surgery was performed only in few series with mastectomy being performed in some of the cases to achieve negative margin. ${ }^{[24,25,27]}$

Notably, a study by Barth et al. in a large review found that the recurrence rate for borderline and malignant PTs remained high even after WLE to the tune of 29 and 35\%, respectively. ${ }^{[15]}$ Similar results were also observed by Hassan et al. with LR rate after WLE being 0,36.4, and $40 \%$ for benign, borderline, and malignant PTs, respectively. ${ }^{[34]}$ This is also supported by other studies that favor histological grade as a predictor of local failure. ${ }^{[27,36,39,41,42]}$ This high rate of local recurrence of borderline and malignant PTs as reported by various authors suggests that wide local excision is probably less than optimal therapy and indicates that additional measures to improve local tumor control should be explored.

Tumor size has been found to have a significant impact on LR. Different series have reported variable cutoff for tumor size ranging from 2 to $>10 \mathrm{~cm}$ [Table $2 \mathrm{~b}$ ]. This is probably related to the differences in the patient demographics among the various studies reported. Overall, it seems to be largely related to the median tumor size. The median tumor size ranges from 5.2 to $10.8 \mathrm{~cm}$ in various studies, and these report $10 \mathrm{~cm}$ as the significant cutoff for LR. ${ }^{[8,25,31,39,43]}$ Studies reporting tumor size $<5 \mathrm{~cm}$ as the significant cutoff have median tumor size in the range of 3.0-6.1 cm. ${ }^{[24,27,31,37]}$ The hazard ratio (HR) has not been reported in most of the studies except in the study by Asoglu et al., where authors have demonstrated tumor size to be an independent predictor of LR in multivariate analysis. ${ }^{[2]}$ Tumor diameter $>5 \mathrm{~cm}$ was associated with a 4-fold increase in LR ( $p=0.0177)$. A retrospective analysis from a large SEER database by Pezner et al. reported that for malignant PT of the breast, LR rates are $15 \%$ or greater for patients with tumors $>2 \mathrm{~cm}$ treated by lumpectomy alone and tumors $>10 \mathrm{~cm}$ treated by mastectomy alone. ${ }^{[31]}$ Authors recommended that adjuvant radiation therapy should be evaluated for these patients as their study showed that local recurrence impacted survival rates.

Among the other factors reported to be prognostic for local and/or distant failure constitute numerous histological factors like stromal cellularity, especially pseudoangiomatous stromal hyperplasia (PASH), stromal overgrowth, stromal atypia, mitotic activity, tumor margin, necrosis, and heterologous stromal elements..$^{[9,24,32,36,38]}$ The investigators from the Singapore Phyllodes Tumor Network developed a predictive nomogram based on three histological criteria (atypia, mitoses, overgrowth) and surgical margin status that can be used for calculating recurrence-free survival of an individual woman diagnosed with PT. ${ }^{[38]}$ Multivariate analysis revealed stromal atypia, overgrowth, and surgical margins to be independently predictive of clinical behavior, with mitoses achieving near significance. Stromal hypercellularity and tumor borders were not independently useful. A nomogram developed based on atypia, mitoses, overgrowth, and surgical margins (AMOS criteria) could predict recurrence-free survival at $1,3,5$, and 10 years. This nomogram was superior to a total histological score derived from adding values assigned to each of five histological parameters. Given the subjectivity in the histological grading 
Table 2: Literature review of selective (year 2001 onward) retrospective series of PT treated with surgery: Descriptive

\begin{tabular}{|c|c|c|c|c|c|c|c|}
\hline Author & $\begin{array}{l}\text { Study } \\
\text { period }\end{array}$ & $\begin{array}{l}\text { No } \\
\text { (N) }\end{array}$ & $\begin{array}{l}\text { Median age/range } \\
\text { (years) }\end{array}$ & $\begin{array}{l}\text { Median tumor } \\
\text { size }(\mathrm{cm})\end{array}$ & $\begin{array}{c}\text { Benign (B) } \\
\mathrm{N}(\%)\end{array}$ & $\begin{array}{c}\text { Borderline } \\
\text { (BL) } \\
\text { N (\%) }\end{array}$ & $\begin{array}{c}\text { Malignant } \\
\text { (MPT) } \\
\text { N (\%) }\end{array}$ \\
\hline Kapiris et al. $2001^{[25]}$ & 1947-1999 & 48 & $47(21-85)$ & $7.8(1.5-20)$ & - & - & $48(100)$ \\
\hline Asoglu et al. $2004^{[24]}$ & $1971-2000$ & 50 & $46(14-77)$ & $3.5(1.5-18)$ & $16(32)$ & $3(6.0)$ & $31(62.0)$ \\
\hline Chen et al. 2005 [32] & $1985-2003$ & 172 & $37(11-73)$ & $5.8(1-30)$ & $131(76)$ & $12(7.0)$ & $29(17.0)$ \\
\hline Tan et al. 2005[33] & 1992-2002 & 335 & $42(16-69)$ & $4.0(0.9-25)$ & $250(74.6)$ & $54(16.1)$ & $31(9.3)$ \\
\hline Hassan $\mathrm{M}$ et al. 2006 ${ }^{[34]}$ & 1988-2003 & 79 & $42(16-70)$ & $11.0(2.5-24)$ & $31(39.2)$ & $27(34.2)$ & $21(26.6)$ \\
\hline Hassouna et al. 2006 $6^{[8]}$ & 1986-2001 & 106 & $39.6(14-71)$ & $8.3(1.5-25)$ & $62(58.4)$ & $16(15.0)$ & $24(26.6)$ \\
\hline Fou et al. 2006 ${ }^{[35]}$ & 1995-2004 & 27 & $46(13-63)$ & $6(2-14)$ & - & - & $27(100.0)$ \\
\hline Taira et al. 2007[36] & 1980-2005 & 45 & $45(28-75)$ & $3.5(1-17)$ & $31(69)$ & $5(11.0)$ & $9(20.0)$ \\
\hline Barrio et al. 2007 & 1954-2005 & 293 & $42(11-83)$ & $8.7(4-20)$ & $203(69)$ & & $90(31.0)$ \\
\hline Pezner et al. 2008 & 1964-2005 & 478 & $53(14-100)$ & $5.2(-)$ & - & - & $478(100.0)$ \\
\hline Lenhard et al. 2008 ${ }^{[42]}$ & 1984-2005 & 33 & $47(18-77)$ & $6.9 \pm 6(1.4-30)$ & $12(40)$ & $10(27.0)$ & $8(33.0)$ \\
\hline Gulliot et al. 2011[27] & 1994-2008 & 165 & $44(17-79)$ & $3.0(0.5-15)$ & $114(69)$ & $37(22.0)$ & $14(9.0)$ \\
\hline Jang et al. $2012^{[37]}$ & 1995-2009 & 164 & $43(11-72)$ & $6.1(1-30)$ & $82(50)$ & $42(25.6)$ & $40(24.4)$ \\
\hline Tan et al. 2012[38] & $1992-2010$ & 605 & $43(15-79)$ & $5.2(0.3-25)$ & $440(72.7)$ & $111(18.4)$ & $54(8.9)$ \\
\hline Ramakant et al. 2013 & 2003-2013 & 150 & Mean 39.24 (15-70) & $10.78(1-30)$ & 77 (51.3) & $24(16.0)$ & $49(32.7)$ \\
\hline Spitaleri et al. $2013^{[40]}$ & 1999-2010 & 172 & $44(11-82)$ & - & $68(39.5)$ & $42(24.5)$ & $62(36.0)$ \\
\hline Kim et al. 2013[41] & 2000-2010 & 193 & Mean 40.5 & 4 (mean) & $145(75.1)$ & $33(17.1)$ & $15(7.8)$ \\
\hline $\begin{array}{l}\text { Narayankar RP et al. } \\
2015^{[43]}\end{array}$ & 2001-2012 & 162 & $38 \pm 8(18-75)$ & $12 \pm 5(3-25)$ & 95 (58.64) & $29(18)$ & $38(23.45)$ \\
\hline Range & $1947-2013$ & $24-605$ & $39-53(11-100)$ & $3.5-17$ & $32-76$ & $6-34.2$ & $7.8-62^{*}$ \\
\hline
\end{tabular}

* Excluding series of malignant subtype alone

Table 2a: Literature review of selective (year 2001 onward) retrospective series of PT: Surgical details and median follow-up

\begin{tabular}{|c|c|c|c|c|c|c|c|}
\hline Author & $\begin{array}{l}\text { LE } \\
\mathrm{N}(\%)\end{array}$ & $\begin{array}{l}\text { WLE } \\
\text { N (\%) }\end{array}$ & $\begin{array}{c}M \\
N(\%)\end{array}$ & $\begin{array}{l}\text { Initial negative } \\
\text { margin } \\
\mathrm{N}(\%)\end{array}$ & $\begin{array}{l}\text { Positive } \\
\text { margin } \\
\mathrm{N}(\%)\end{array}$ & $\begin{array}{c}\text { Final negative } \\
\text { margin } \\
N(\%)\end{array}$ & $\begin{array}{l}\text { Median follow-up } \\
\text { (months) }\end{array}$ \\
\hline${ }^{*}$ Kapiris et al. $2001^{[25]}$ & $10(21.0)$ & $14(29.0)$ & $24(50.0)$ & $18(53)$ & $16(47)$ & $21(61.7)$ & $108(5-336)$ \\
\hline Asoglu et al. 2004[24] & - & $22(44.0)$ & $28(56.0)$ & $42(84)$ & $8(16)$ & $50(100)$ & $91(12-360)$ \\
\hline Chen et al. 2005 ${ }^{[32]}$ & $71(41.3)$ & $55(32.0)$ & $46(26.7)$ & $159(92.4)$ & $13(7.6)$ & - & $71(7-237)$ \\
\hline Tan et al. 2005[33] & $272(81.2)$ & 39 (11.6) & $23(6.9)$ & $139(41.6)$ & $195(58.4)$ & - & 20.4 \\
\hline Hassan M et al. 2006 & $22(27.8)$ & $24(30.4)$ & $33(41.8)$ & - & - & - & $60(3-138)$ \\
\hline Hassouna et al. $2006^{[8]}$ & $82(77.4)$ & - & $24(22.6)$ & $65(61.3)$ & $4(3.77)$ & - & $43(1-216)$ \\
\hline Fou et al. 2006 ${ }^{[35]}$ & $17(65.0)$ & - & $9(35.0)$ & $8(29.6)$ & $18(66.7)$ & - & $52(12-192)$ \\
\hline Taira et al. 2007[36] & 15 (33.3) & $27(60.0)$ & $3(6.7)$ & $30(67)$ & $15(33)$ & - & $101(1-273)$ \\
\hline "Barrio et al. 2007[9] & - & $242(83.0)$ & $48(16.0)$ & $174(59)$ & $60(21)$ & - & $7.9(0.01-44)$ \\
\hline Pezner et al. 2008 ${ }^{[31]}$ & $169(45.0)$ & - & $207(55.0)$ & - & - & - & $64(0-410)$ \\
\hline Lenhard et al. 2008 ${ }^{[42]}$ & - & $19(59.0)$ & $13(41.0)$ & $33(100)$ & $0(0)$ & - & $87(1-222)$ \\
\hline Gulliot et al. 2011[27] & - & $154(93.3)$ & $11(6.7)$ & $119(72)$ & $46(28)$ & $139(84.2)$ & $12.65(0-149.8)$ \\
\hline Jang et al. $2012^{[37]}$ & \multicolumn{2}{|c|}{$148(90.2)$} & $16(9.8)$ & $142(86.6)$ & $22(13.4)$ & - & $33.6(2-179)$ \\
\hline Tan et al. 2012[38] & $376(62.0)$ & $114(18.8)$ & $62(10.2)$ & $349(57.7)$ & $256(42.3)$ & - & $1,3,5,10$ yrs \\
\hline Ramakant et al. $2013^{[39]}$ & $61(40.6)$ & $33(22.0)$ & $56(37.4)$ & - & - & - & NA \\
\hline Spitaleri et al. $2013^{[40]}$ & - & $137(80.0)$ & $35(20.0)$ & $161(94.2)$ & $10(5.9)$ & - & 120 \\
\hline Kim et al. 2013[41] & $143(74.1)$ & $39(20.2)$ & $11(5.7)$ & $167(86.5)$ & $26(13.5)$ & - & NA \\
\hline Narayankar RP et al. 2015 & $49(30)$ & $50(31)$ & $63(39)$ & - & - & - & $36(12-60)$ \\
\hline Range & $21-90 \%$ & $11.6-97 \%$ & $3-56 \%$ & $29.6-100$ & $5.9-66.7$ & & $7.9-120$ \\
\hline
\end{tabular}

*Histopathology was available for 34 patients only

"Margin status was not known in 59(20\%) patients

LE: Local excision, WLE: Wide local excision, M: Mastectomy, N: Number

of PT as discussed previously, objective risk assessment tools like the Tan's nomogram once validated in larger and diverse datasets can be applied for patient counseling and clinical management.
Age at presentation has also been described as a predictive factor for LR, but the results are contradictory. In a review by Spitaleri et al., it has been shown that young age ( $<35$ years) is a poor prognostic factor for all phyllodes-related events 
Table 2b: Literature review of selective retrospective series of PT treated with surgery exclusive: Local recurrence rate and predictors of local failure ${ }^{\circledR}$

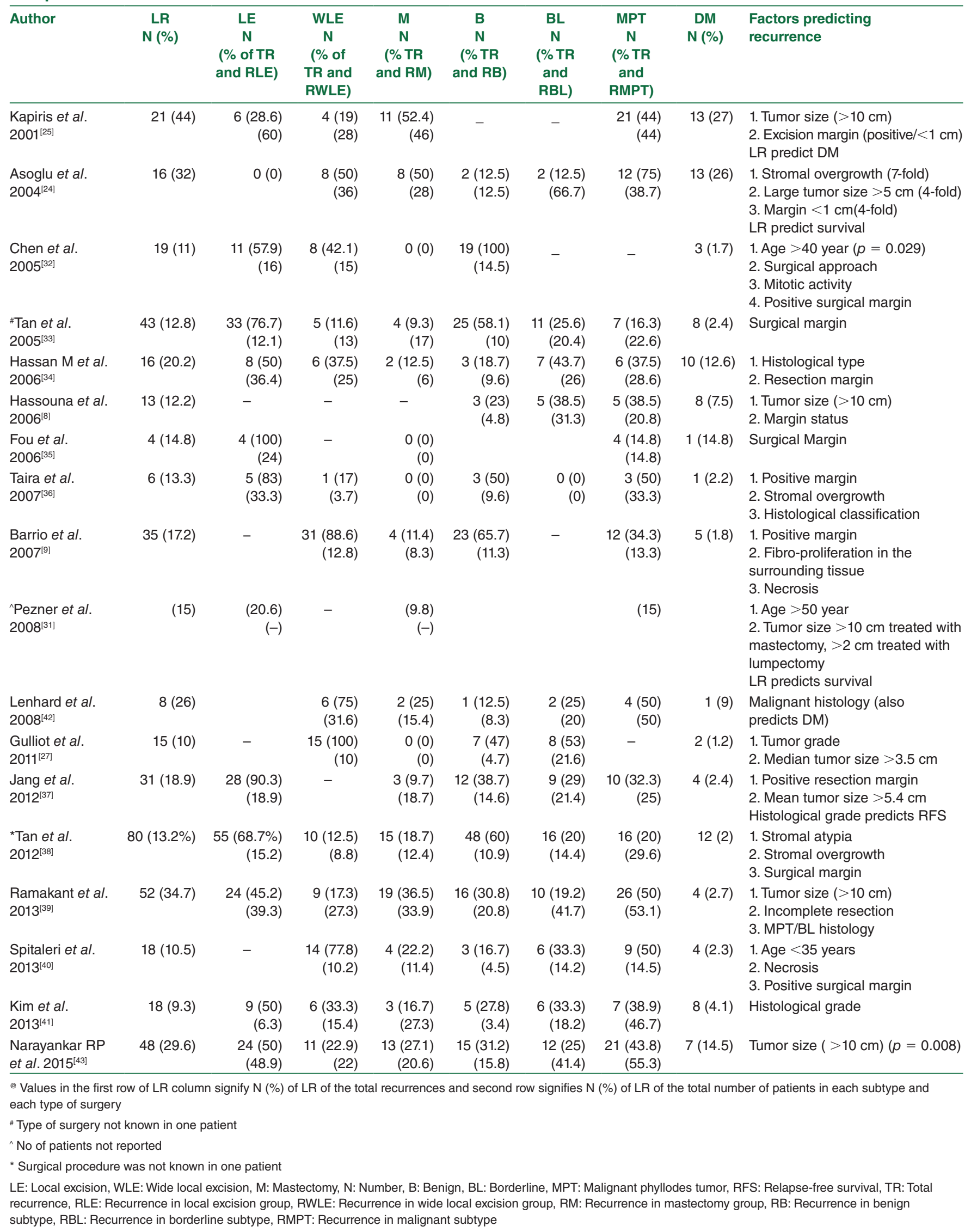


in both univariate and multivariate analyses. ${ }^{[40]}$ Similarly, Pandey et al. reported that women over the age of 35 years showed a decreased HR $(\mathrm{HR}=0.7) \cdot{ }^{[44]}$ However, a majority of the studies indicate advance age ( $>50$ years) as the indicator of LR as well as survival. ${ }^{[30,31,45,46]}$ This could be explained by the fact that the incidence of malignant histology increases with age. ${ }^{[25,47]}$

Whether LR is a predictor for the development of systemic metastasis remains a controversial issue. Some authors have shown that up to $60 \%$ of patients with systemic metastasis develop prior $\mathrm{LR}^{[25,48-50]}$ while some others refute this association. ${ }^{[10,11,23]}$ LR or factors affecting LR may adversely affect survival for PT as well, similar to breast cancer. In a large study, Pezner et al. demonstrated that survival is negatively affected by LR with a HR of $2.5(p<0.05) .{ }^{[31]}$ Similarly, Asoglu et al. found that close surgical margins, which are a predictor of LR, also adversely affected survival. ${ }^{[24]}$ These studies highlight the significance of local control and the need of adjuvant treatment for decreasing the incidence of LR, which may translate into improvement in survival.

Of the different risk factors described in the literature, most relevant factors are mentioned in Table 3. Tumor size, age, and tumor necrosis in addition to AMOS (i.e., NAMMOSS) can be useful for evaluating the risk of local recurrence. It would be advisable to include these factors in the nomogram as well as validate the results in large datasets.

\section{Efficacy of adjuvant radiotherapy}

Though PT has excellent 5- and 10-year overall survival rates with a range of 89 to $97 \%$, higher relapse rate even after adequate resection in malignant and borderline subtypes is a major problem, thereby defining the necessity of adjuvant treatment. ${ }^{[30,46]}$ As discussed previously, the role of adjuvant therapies (radiotherapy and chemotherapy) have not been clearly defined in the treatment of PT. Hence, adjuvant therapies are not routinely offered in clinical practice, which is also reflected in very few percentage $(<10 \%)$ of patients receiving adjuvant $\mathrm{RT}$ in a majority of the reported series. ${ }^{[24,30,31,51]}$

The role of radiation therapy for PT specifically in borderline and malignant histology remains unclear, since clinical data supporting the use of adjuvant radiation is based on anecdotal case reports or on small patient series. Radiotherapy is usually offered to patients with local recurrence, positive margins, or symptomatic metastases (i.e., bone). However, retrospective

Table 3: Factors associated with local recurrence in phyllodes tumors of the breast (NAMMOSS)

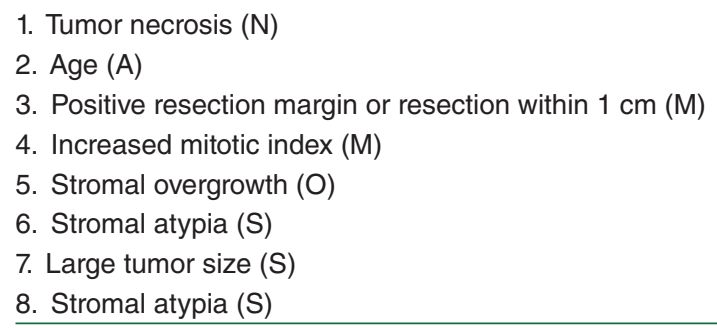

studies suggest that adjuvant RT may be underutilized in the treatment of PT of the breast, particularly in patients with adverse features. Reported studies have shown better local tumor control without affecting survival.

McGowan et al. published a combined analysis of breast sarcomas $(n=78)$ inclusive of cystosarcoma phyllodes $(n=32)$. Radiotherapy was used in $10 / 32(31 \%)$ patients having malignant PT with equal numbers following lumpectomy or mastectomy. Margins were positive in four patients. The 5- and 10 -year local relapse free rates were each $74 \%$ for the entire cohort but did not provide a separate analysis of local control for malignant PT patients. Seventeen of the eighteen local failures were diagnosed within 4 years of initial presentation. ${ }^{\text {[52] }}$ Due to small numbers, the subgroup analysis testing benefit of radiation in lumpectomy and mastectomy group did not result in any statistically significant difference in clinical outcome. Nonetheless, analyzing the outcome as per radiation dose $(\leq 48$ Gray (Gy), $>48 \mathrm{~Gy}$, or none) resulted in better 5-year causespecific survival in the higher radiation group (91 vs. 50\%).

Similarly, the SAPHYR study (SArcoma and PHYllode Retrospective), a French retrospective pooled analysis of primary breast sarcomas $(n=44)$ and PT $(n=26)$, defined three significantly ( $p=0.0003$ ) different prognostic groups in terms of disease-free survival (DFS) depending upon the histology, with malignant PT having intermediate survival as compared to benign PT and angiosarcoma. Moreover, malignant PT behaved similar to other breast sarcomas, excluding angiosarcomas (3-year DFS 45.7\%, $p=0.51$ ). Adjuvant RT was given to 23 patients of the entire cohort ( $24 \%$ post wide excision and $39 \%$ post mastectomy). Though there was a trend toward improved survival for the group with tumor size $5 \mathrm{~cm}$ or less (survival rate 57.7 versus $46.7 \%$ ), the difference was not statistically significant. ${ }^{[45]}$

Chaney et al. reported eight cases of patients who received adjuvant RT at a dose of 60 Gy. ${ }^{[51]}$ Radiotherapy was administered for a combination of reasons, including bulky tumor volume, positive margins, recurrence, and/or malignant histology. None of the patients treated for malignant tumors developed recurrence. In the series of Pandey et al. from South India, 25 of 37 patients with a malignant PT who received postoperative RT had better 5-year DFS (61 vs. 25\%) at a median follow-up of 43 months, but the difference was not statistically significant $(p=0.16) \cdot{ }^{[44]}$ However, patients with tumor size more than $5 \mathrm{~cm}(\mathrm{HR})=2.9)$ were found to have increased hazard when analyzed for DFS.

Given the proven role of radiation therapy for adjuvant treatment of soft tissue sarcomas, analogy suggests that radiotherapy should be considered following wide excision of high-risk (i.e., malignant) phyllodes tumors. Hence, August and Kearney recommended adjuvant RT for highrisk PT: tumor size $>5 \mathrm{~cm}$, stromal overgrowth $>10$ mitosis / $\mathrm{HPF}$, or infiltrative margins. ${ }^{[53]}$ Similarly, in a study including patients with large tumors (mean tumor size $=10 \mathrm{~cm}$ ), all patients with LR also developed distant metastases. Thus, the investigators recommended adjuvant RT for all malignant PT irrespective of the type of surgery. ${ }^{[54]}$ Similarly, the use 
Wadasadawala, et al:: Phyllodes tumor of the breast

Table 4: Literature review of selective series of patients of PT treated with lumpectomy/mastectomy with or without radiotherapy

\begin{tabular}{|c|c|c|c|c|c|c|c|c|c|}
\hline Author & $\begin{array}{l}\text { Study } \\
\text { period }\end{array}$ & $\begin{array}{l}\text { No } \\
\text { (n) }\end{array}$ & $\begin{array}{c}\text { Histology } \\
(\%)\end{array}$ & $\begin{array}{c}\text { Mean } \\
\text { tumor } \\
\text { size in cm } \\
\text { (range) }\end{array}$ & $\begin{array}{c}\text { Number } \\
\text { received } \\
\text { radiation } \\
\mathrm{N}(\%)\end{array}$ & $\begin{array}{c}\text { Radiation } \\
\text { dose }\end{array}$ & $\begin{array}{c}\text { Median } \\
\text { follow-up } \\
\text { (month) }\end{array}$ & $\begin{array}{l}\text { LR } \\
(\%)\end{array}$ & Remark \\
\hline Chaney et al. 1998 ${ }^{[51]}$ & 1988-1993 & 8 & $\begin{array}{c}\mathrm{B}(25) \\
\mathrm{BL}(12.5) \\
\operatorname{MPT}(62.5)\end{array}$ & - & $8(100)$ & 60-70 Gy & 36.5 & None & - \\
\hline McGowan et al. 2000[52] & 1958-1990 & 32 & MPT (100) & $\begin{array}{c}5 \\
(1.5-40)\end{array}$ & $10(31 \%)$ & 40-60 Gy & $114(10.8-372)$ & $\begin{array}{c}26 \% \\
\text { overall }\end{array}$ & $\begin{array}{l}\text { No separate } \\
\text { analysis for MPT }\end{array}$ \\
\hline Pandey et al. 2001 ${ }^{[44]}$ & 1982-1998 & 37 & MPT (100) & - & $37(100)$ & NA & $43(1-170)$ & $21 \%$ & - \\
\hline Soumarov et al. $2004^{[54]}$ & 1970-1995 & 25 & MPT (100) & 10 & $17(68)$ & 46-70 Gy & 139.5 & $4(16)$ & $\begin{array}{l}\text { All patients with } \\
\text { LR had DM }\end{array}$ \\
\hline Confavreux et al. 2006 ${ }^{[45]}$ & 1966-2004 & 26 & $\begin{array}{c}\text { B (19.2) } \\
\text { BL (19.2) } \\
\text { MPT (61.6) }\end{array}$ & $\begin{array}{c}4.75 \\
(1-21)\end{array}$ & - & - & - & - & $\begin{array}{l}\text { RT made no } \\
\text { difference }\end{array}$ \\
\hline Belkacemi et al. 2008[46] & 1971-2003 & 443 & $\begin{array}{c}\mathrm{B}(64.1) \\
\mathrm{BL}(18.1) \\
\operatorname{MPT}(17.8)\end{array}$ & 4.6 & $39(9 \%)$ & 37-60 Gy & $106(12-387)$ & - & $\begin{array}{l}\text { Factors for LR } \\
\text { RT, margins, } \\
\text { benign histology } \\
p=0.02 \text { for RT }\end{array}$ \\
\hline Bouhafa et al. 2009[55] & 1998-2006 & 53 & $\begin{array}{c}\mathrm{B}(22) \\
\mathrm{BL}(36) \\
\operatorname{MPT}(35)\end{array}$ & 10.25 & $16(28 \%)$ & $\begin{array}{c}50 \text { Gy } \\
15 \text { Gy boost }\end{array}$ & 36 & 10 & - \\
\hline${ }^{\star}$ Barth et al. 2009[56] & - & 46 & $\begin{array}{c}\mathrm{MPT}(65) \\
\mathrm{BL}(35)\end{array}$ & $\begin{array}{c}3.7 \\
(0.8-11)\end{array}$ & $46(100)$ & $\begin{array}{c}50.4 \text { Gy } \\
10 \text { Gy boost }\end{array}$ & $56(12-129)$ & None & $\begin{array}{l}\text { Margin-negative } \\
\text { resection } \\
\text { Adjuvant RT }\end{array}$ \\
\hline Spitaleri et al. 2013 ${ }^{[40]}$ & 1999-2010 & 172 & $\begin{array}{c}\text { Benign (39.6) } \\
\text { BT }(24.4) \\
\text { MPT }(36)\end{array}$ & - & $9(5.2)$ & - & $85(4.5-268)$ & None & - \\
\hline
\end{tabular}

* Only prospective study

LR: Local recurrence, B: Benign, BL: Borderline, MPT: Malignant Phyllodes tumor, RT: Radiotherapy

of RT for tumors with high risk of local recurrence has been proposed by Bouhfa et al. ${ }^{[55]}$ In a retrospective analysis by Spitaleri et al., of nine patients who received adjuvant RT, none of them relapsed. ${ }^{[40]}$

In two recent studies, adjuvant RT was associated with better local control. Belkacemi et al. conducted a retrospective study as a part of Rare Cancer Network that included a total of 443 patients with PT. ${ }^{[46]}$ In this study, tumors were benign in 284 cases $(64 \%)$, borderline in 80 cases (18\%), and malignant in 79 cases $(18 \%)$. Surgical treatment consisted of breast-conserving surgery and total mastectomy in 85 and $15 \%$, respectively. Only $9 \%$ of patients received adjuvant RT. Median RT dose was 50 Gy (range: 37-60 Gy). In the malignant and borderline groups $(n=60)$, the only favorable independent prognostic factor for local control was the use of $\mathrm{RT}(\mathrm{RR}=3.30 ; p=0.001)$ on multivariate analysis. The 10-year local control was 59 vs. $86 \%$ in this group ( $p=0.02)$. In another nonrandomized prospective study, 46 patients with borderline or malignant PTs who underwent breast-conserving surgery (median size of negative margins $0.35 \mathrm{~cm}$ and median tumor size $3.7 \mathrm{~cm}$ ) were treated with adjuvant RT. In this study, after a median follow-up of 56 months, none of the 46 patients developed local recurrence. ${ }^{[56]}$ The systematic review and metaanalysis on the effect of adjuvant RT on borderline and malignant PTs concluded that the use of adjuvant RT decreases the incidence of local recurrence $(\mathrm{HR}=0.43)$, especially in those who received radiotherapy following breast conservation surgery. However, this did not translate into improved OS or DFS. ${ }^{[57]}$

A prospective study by Barth et al. is actively recruiting patients of borderline and malignant PTs for partial breast irradiation after margin-negative surgery by either external beam radiotherapy or mammosite with LR as primary endpoint. The study would explore the role of partial breast irradiation in PT of the breast. ${ }^{[58]}$

The role of chemotherapy in PT of the breast is also debatable. There are isolated case reports of the role of chemotherapy in PT. A small randomized study of four cycles of chemotherapy (doxorubicin plus dacarbazine) versus observation showed no survival advantage for patients of malignant PT. ${ }^{[59]}$ Apart from this, the literature on adjuvant chemotherapy is sparse. Small case series show some advantage of ifosfamidecontaining regimen in recurrent setting.

\section{Conclusions}

Surgery remains the mainstay of treatment for PT. Optimal surgery with negative margin is the key to reduce incidence of local recurrence. Though radiotherapy seems to be a viable option for reducing $L R$, its role should be tested 
prospectively in a randomized setting. Patients with borderline and malignant PTs with adverse histological features (margins $<1 \mathrm{~cm}$ irrespective of other risk factors and in the case of wide margins tumors with additional risk factors like tumor size more than $2 \mathrm{~cm}$, stromal overgrowth, mitosis $\geq 5 / \mathrm{HPF}$, stromal atypia, tumor necrosis, and elderly age) should be encouraged to participate in clinical trials. Out-of-trial patients should be explained about the limited evidence for the benefits of adjuvant RT due to overall rarity of the disease as well as sparse use of adjuvant radiation in the reported series. However, the potential of adjuvant radiation in reducing local recurrence (and possibly distant failure) without affecting survival and preventing morbidity of additional surgery in one fourth of patients should be equally emphasized. Chemotherapy is indicated when there is recurrent/metastatic disease, and largely management lines are similar as per the soft tissue sarcoma therapies.

One should be cautious in dealing with this unique, simple but complex entity; beware, there can be wolf underneath the sheep's skin!

\section{References}

1. Azzopardi J. Sarcoma in the breast. In: Bennington J editor. Problems in Breast Pathology. Major Problems in Pathology. Philadelphia, PA: WB Saunders Co.; 1979. p. 355-59.

2. Reinfuss M, Mitus J, Duda K, Stelmach A, Rys J, Smolak K. The treatment and prognosis of patients with phyllodes tumor of the breast: An analysis of 170 cases. Cancer 1996;77:910-6.

3. Fiks A. Cystosarcoma phyllodes of the mammary glandMuller's tumor. For the 180th birthday of Johannes Muller. Virchows Arch A Pathol Anat Histol 1981;392:1-6.

4. World Health Organization. Histologic Typing of Breast Tumors. 2nd ed. Geneva, Switzerland: WHO; 1981.

5. Ridgway PF, Jacklin RK, Ziprin P, Harbin L, Peck DH, Darzi AW, et al. Perioperative diagnosis of cystosarcoma phyllodes of the breast may be enhanced by MIB-1 index. J Surg Res 2004;122:83-88.

6. Jacklin RK, Ridgway PF, Ziprin P, Healy V, Hadjiminas D, Darzi A. Optimising preoperative diagnosis in phyllodes tumour of the breast. J Clin Pathol 2006;59:454-9.

7. Parker SJ, Harries SA. Phyllodes tumours. Postgrad Med J 2001;77:428-35.

8. Ben Hassouna J, Damak T, Gamoudi A, Chargui R, Khomsi F, Mahjoub S, et al. Phyllodes tumors of the breast: A case series of 106 patients. Am J Surg 2006;192:141-7.

9. Barrio AV, Clark BD, Goldberg JI, Hoque LW, Bernik SF, Flynn $\mathrm{LW}$, et al. Clinicopathologic features and long-term outcomes of 293 phyllodes tumors of the breast. Ann Surg Oncol 2007;14:2961-70.

10. Rosen P. Cystosarcoma Phyllodes. In: Rosen's Breast Pathology: Fibroepithelial neoplasms. Philadelphia, PA: Lippincott; 1996. p. 155-75.

11. Norris HJ, Taylor HB. Relationship of histologic features to behavior of cystosarcoma phyllodes. Analysis of ninety-four cases. Cancer 1967;20:2090-9.

12. Rowell MD, Perry RR, Hsiu JG, Barranco SC. Phyllodes tumors. Am J Surg 1993;165:376-9.

13. Gullett NP, Rizzo M, Johnstone PA. National surgical patterns of care for primary surgery and axillary staging of phyllodes tumors. Breast J 2009;15:41-44.
14. Bartoli C, Zurrida S, Veronesi P, Bono A, Chiesa F, Cosmacini P, et al. Small sized phyllodes tumor of the breast. Eur J Surg Oncol 1990;16:215-9.

15. Barth RJ, Jr. Histologic features predict local recurrence after breast conserving therapy of phyllodes tumors. Breast Cancer Res Treat 1999;57:291-5.

16. Yagishita M, Nambu Y, Ishigaki M, Okada T, Yamanouchi K, Toga $\mathrm{H}$, et al. [Pulmonary metastatic malignant phyllodes tumor showing multiple thin walled cavities]. Nihon Kokyuki Gakkai zasshi 1999;37:61-66.

17. Naruns PL, AE. G. Sarcomas of the breast. In: Eilber FR MD, Sondak VK, Economou JS, editor. The Soft Tissue Sarcomas. New York: Grune \& Stratton; 1987. p. 169-82.

18. Yilmaz E, Sal S, Lebe B. Differentiation of phyllodes tumors versus fibroadenomas. Acta Radiol 2002;43:34-39.

19. Farria DM, Gorczyca DP, Barsky SH, Sinha S, Bassett LW. Benign phyllodes tumor of the breast: MR imaging features. AJR Am J Roentgenol 1996;167:187-9.

20. Jorge Blanco A, Vargas Serrano B, Rodriguez Romero R, Martinez Cendejas E. Phyllodes tumors of the breast. Eur Radiol 1999;9:356-60.

21. Vorherr H, Vorherr UF, Kutvirt DM, Key CR. Cystosarcoma phyllodes: Epidemiology, pathohistology, pathobiology, diagnosis, therapy, and survival. Arch Gynecol 1985;236:173-81.

22. Tavassoéli FA, P D. Pathology and Genetics Tumours of the Breast and Female Genital Organs. World Health Organization Classification of Tumors. Lyon: International Agency for Research on Cancer; 2003. p. 99-103.

23. Moffat CJ, Pinder SE, Dixon AR, Elston CW, Blamey RW, Ellis IO. Phyllodes tumours of the breast: A clinicopathological review of thirty-two cases. Histopathology 1995;27:205-18.

24. Asoglu O, Ugurlu MM, Blanchard K, Grant CS, Reynolds C, Cha SS, et al. Risk factors for recurrence and death after primary surgical treatment of malignant phyllodes tumors. Ann Surg Oncol 2004;11:1011-7.

25. Kapiris I, Nasiri N, A'Hern R, Healy V, Gui GP. Outcome and predictive factors of local recurrence and distant metastases following primary surgical treatment of high-grade malignant phyllodes tumours of the breast. Eur J Surg Oncol 2001;27:723-30.

26. Zurrida S, Bartoli C, Galimberti V, Squicciarini P, Delledonne V, Veronesi $\mathrm{P}$, et al. Which therapy for unexpected phyllode tumour of the breast? Eur J Cancer 1992;28:654-7.

27. Guillot E, Couturaud B, Reyal F, Curnier A, Ravinet J, Lae $\mathrm{M}$, et al. Management of phyllodes breast tumors. Breast J 2011;17:129-37.

28. Geisler DP, Boyle MJ, Malnar KF, McGee JM, Nolen MC, Fortner $\mathrm{SM}$, et al. Phyllodes tumors of the breast: A review of 32 cases. Am Surg 2000;66:360-6.

29. Khan SA, Badve S. Phyllodes tumors of the breast. Curr Treat Options Oncol 2001;2:139-47.

30. Macdonald OK, Lee CM, Tward JD, Chappel CD, Gaffney DK Malignant phyllodes tumor of the female breast: Association of primary therapy with cause-specific survival from the Surveillance, Epidemiology, and End Results (SEER) program. Cancer 2006;107:2127-33.

31. Pezner RD, Schultheiss TE, Paz IB. Malignant phyllodes tumor of the breast: Local control rates with surgery alone. Int J Radiat Oncol Biol Phys 2008;71:710-3.

32. Chen WH, Cheng SP, Tzen CY, Yang TL, Jeng KS, Liu CL, et al. Surgical treatment of phyllodes tumors of the breast: Retrospective review of 172 cases. J Surg Oncol 2005;91:185-94.

33. Tan PH, Jayabaskar T, Chuah KL, Lee HY, Tan Y, Hilmy M, et al. Phyllodes tumors of the breast: The role of pathologic parameters. Am J Clin Pathol 2005;123:529-40. 
34. Abdalla HM, Sakr MA. Predictive factors of local recurrence and survival following primary surgical treatment of phyllodes tumors of the breast. J Egypt Natl Cancer Inst 2006;18:125-33.

35. Fou A, Schnabel FR, Hamele-Bena D, Wei XJ, Cheng B, El Tamer $\mathrm{M}$, et al. Long-term outcomes of malignant phyllodes tumors patients: An institutional experience. Am J Surg 2006;192:492-5.

36. Taira N, Takabatake D, Aogi K, Ohsumi S, Takashima S, Nishimura R, et al. Phyllodes tumor of the breast: Stromal overgrowth and histological classification are useful prognosispredictive factors for local recurrence in patients with a positive surgical margin. Jpn J Clin Oncol 2007;37:730-6.

37. Jang JH, Choi MY, Lee SK, Kim S, Kim J, Lee J, et al. Clinicopathologic risk factors for the local recurrence of phyllodes tumors of the breast. Ann Surg Oncol 2012;19:2612-7.

38. Tan PH, Thike AA, Tan WJ, Thu MM, Busmanis I, Li H, et al. Predicting clinical behaviour of breast phyllodes tumours: A nomogram based on histological criteria and surgical margins. J Clin Pathol 2012;65:69-76.

39. Ramakant P, Chakravarthy S, Cherian JA, Abraham DT, Paul MJ. Challenges in management of phyllodes tumors of the breast: A retrospective analysis of 150 patients. Indian J Cancer 2013;50:345-8

40. Spitaleri G, Toesca A, Botteri E, Bottiglieri L, Rotmensz N, Boselli $S$, et al. Breast phyllodes tumor: A review of literature and a single center retrospective series analysis. Crit Rev Oncol Hematol 2013;88:427-36.

41. Kim S, Kim JY, Kim do H, Jung WH, Koo JS. Analysis of phyllodes tumor recurrence according to the histologic grade. Breast Cancer Res Treat 2013;141:353-63.

42. Lenhard MS, Kahlert S, Himsl I, Ditsch N, Untch M, Bauerfeind I. Phyllodes tumour of the breast: Clinical follow-up of 33 cases of this rare disease. Eur J Obstet Gynecol Reprod Biol 2008;138:217-21.

43. Narayanakar RP, Gangaiah DM, Althaf S, Dev K, Kurpad V, Gurawalia J. Cystosarcoma phyllodes: Pathological enigma: A retrospective review of 162 cases. Indian J Cancer 2015;52:365-8.

44. Pandey M, Mathew A, Kattoor J, Abraham EK, Mathew BS, Rajan B, et al. Malignant phyllodes tumor. Breast J 2001;7:411-6.

45. Confavreux C, Lurkin A, Mitton N, Blondet R, Saba C, Ranchere $\mathrm{D}$, et al. Sarcomas and malignant phyllodes tumours of the breast--a retrospective study. Eur J Cancer 2006;42:2715-21.

46. Belkacemi Y, Bousquet G, Marsiglia H, Ray-Coquard I, Magne N, Malard Y, et al. Phyllodes tumor of the breast. Int J Radiat Oncol Biol Phys 2008;70:492-500.

47. Niezabitowski A, Lackowska B, Rys J, Kruczak A, Kowalska T, Mitus J, et al. Prognostic evaluation of proliferative activity and DNA content in the phyllodes tumor of the breast: Immunohistochemical and flow cytometric study of 118 cases. Breast Cancer Res Treat 2001;65:77-85.

48. Hajdu SI, Espinosa MH, Robbins GF. Recurrent cystosarcoma phyllodes: A clinicopathologic study of 32 cases. Cancer 1976;38:1402-6.
49. West TL, Weiland LH, Clagett OT. Cystosarcoma phyllodes. Ann Surg 1971;173:520-8.

50. Faraci RP, Schour L. Radical treatment of recurrent cytosarcoma phylloides. Ann Surg 1974;180:796-8.

51. Chaney AW, Pollack A, McNeese MD, Zagars GK. Adjuvant radiotherapy for phyllodes tumor of breast. Radiat Oncol Investig 1998;6:264-7.

52. McGowan TS, Cummings BJ, O'Sullivan B, Catton CN, Miller N, Panzarella T. An analysis of 78 breast sarcoma patients without distant metastases at presentation. Int J Radiat Oncol Biol Phys 2000;46:383-90.

53. August DA, Kearney T. Cystosarcoma phyllodes: Mastectomy, lumpectomy, or lumpectomy plus irradiation. Surg Oncol 2000;9:49-52.

54. Soumarova R, Seneklova Z, Horova H, Vojkovska H, Horova I, Budikova M, et al. Retrospective analysis of 25 women with malignant cystosarcoma phyllodes--treatment results. Arch Gynecol Obstet. 2004;269:278-81.

55. Bouhafa T, Masbah O, Bekkouch I, Afqir S, Mellas N, Ismaili N, et al. [Phyllodes tumors of the breast: Analysis of 53 patients]. Cancer Radiother 2009;13:85-91.

56. Barth RJ, Jr., Wells WA, Mitchell SE, Cole BF. A prospective, multiinstitutional study of adjuvant radiotherapy after resection of malignant phyllodes tumors. Ann Surg Oncol 2009;16:2288-94.

57. Zeng S, Zhang X, Yang D, Wang X, Ren G. Effects of adjuvant radiotherapy on borderline and malignant phyllodes tumors: A systematic review and meta-analysis. Mol Clin Oncol 2015;3:663-71.

58. Barth R. A Prospective Study of Partial Breast Adjuvant Radiation Therapy After Resection of Borderline and Malignant Phyllodes Tumors. Lebanon, NH: Dartmouth-Hitchcock Medical Center; 2010.

59. Morales-Vasquez F, Gonzalez-Angulo AM, Broglio K, LopezBasave HN, Gallardo D, Hortobagyi GN, et al. Adjuvant chemotherapy with doxorubicin and dacarbazine has no effect in recurrence-free survival of malignant phyllodes tumors of the breast. Breast J 2007;13:551-6.

This is an open access article distributed under the terms of the Creative Commons Attribution-NonCommercial-ShareAlike 3.0 License, which allows others to remix, tweak, and build upon the work non-commercially, as long as the author is credited and the new creations are licensed under the identical terms.

How to cite this article: Wadasadawala T, Swain M, Bajpai J. Phyllodes tumor of the breast: Wolf inside the sheep's skin! Oncobiol Targets 2016;3:10.

Source(s) of Support: None. Conflicting Interest: None. 